\title{
The Structure of Rat Liver Triglycerides ${ }^{1}$
}

SISTER P. M. SLAKEY ${ }^{2}$ and W. E. M. LANDS, The University of Michigan, Ann Arbor, Michigan

\begin{abstract}
The fatty acid compositions at the 1-, 2-, and 3-positions ${ }^{3}$ of rat liver triglycerides were determined by using pancreatic lipase and diglyceride kinase. The distribution of acids between the 1- and 3positions is not random; rather each position has a characteristic composition. The relative abundance of species and positional isomers in the triglyceride mixture was predicted by using values from the stereospecific analysis and assuming that the composition of each position is independent of the other two. The total triglyceride was resolved into species by using TLC with silver nitrate and Silica Gel $\mathrm{G}$, and the relative amounts corresponded closely with those predicted on the basis of this assumption.
\end{abstract}

The major species were isolated, and the distribution of their fatty acids among the three glyceride positions was determined. From these data the relative amount of each positional isomer was calculated. The results indicate that the esterification of fatty acids at each position proceeds with a specificity that is not correlated with the composition of the other positions of the molecule.

The relative abundance of the different liver triglyceride species is also found to be related in part to the composition of the 1,2-diglyceride units found in the lecithins of this tissue.

\section{INTRODUCTION}

The metabolic step in which the 3-posi1 tion of triglycerides is acylated may influence the over-all fatty acid composition of the triglyceride fraction in two ways: by preferentially incorporating certain 1,2-diglyceride units and by selecting particular acyl groups for esterification. Weiss et al. (2) and Goldman and Vagelos (3) attempted to show specificity for certain diglycerides in the syn-

\footnotetext{
1 Presented at the AOCS Meeting, Philadelphia, October 1966.

2National Science Foundation Graduate Fellow. Present address: Saint Dominic College, Saint Charles, Ill.

${ }^{8}$ The stereospecific numbering system recommended by Hirschmann (1) is used throughout this paper.
}

thesis of triglycerides but were hampered by the difficulty of dealing with insoluble subtrates. Gøransson (4) showed that the ratio of incorporated oleate to palmitate in rat liver triglycerides was much higher than that of the diglycerides, suggesting that a preferential esterification of oleate relative to palmitate occurs at the 3-position in vivo:

A recent finding (5) that, in rat liver, the fatty acid composition at the 3-position varies dramatically from that at the 1-position reinforces the suggestion of a 3-acylating system which has some specificity for the acid to be esterified. The present study deals with the analysis of the distribution of fatty acids among the three positions in individual triglyceride species.

The stereospecific analysis is summarized in Fig. 1. Triglycerides are incubated with pancreatic lipase, which hydrolyzes the primary ester linkages to yield a mixture of 1,2- and 2,3-diglycerides, which are further degraded to 2-monoglycerides. The reaction may be stopped at a stage of partial hydrolysis and the mixed diglycerides recovered and incubated with ATP and the diglyceride kinase from Escherichia coli. This enzyme phosphorylates only the 1,2-diglyceride to yield a phosphatidic acid which contains the fatty acids originally at the 1- and 2-positions of the triglycerides. The composition of the 1position is found by the differences between the phosphatidic acid and the monoglyceride fractions. The composition at the 2-position is that of the isolated monoglyceride, and the composition of the 3-position is found by the differences between the triglyceride and the phosphatidic acid fractions.
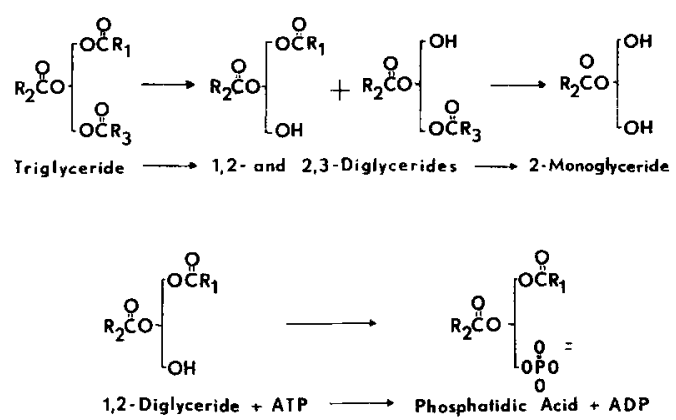

Fig. 1. Stereospecific analysis of trigiycerides. 


\section{EXPERIMENTAL PROCEDURES}

\section{Preparation of Enzymes}

Lipase was prepared as described previously (5). The preparation used for routine triglyceride analysis had a specific activity of 270 units/mg, as measured by a micro-adaptation of the method of Desneulle (6). One unit of activity equals $1 \mathrm{meq}$ of ester hydrolyzed per minute per milliliter. Before each lipase preparation was used, its activity under the conditions used for triglyceride analysis was determined. Triglyceride samples $(5 \mathrm{mg}$ ) were treated with lipase for $0,1,2,3,4$, or $5 \mathrm{~min}$. Aliquots of the lipid extracts were chromatographed on silicic acid plates to determine the diglyceride content. The time which gave the maximum yield of diglyceride was then used for the stereospecific analysis.

Diglyceride kinase was prepared as described by Pieringer and Kunnes (7). After heat treatment it was stored at $-10 \mathrm{C}$ in $0.01 \mathrm{M}$ sodium phosphate $-0.1 \%$ cysteine hydrochloride buffer. No loss of activity was observed after three to four months.

\section{Chromatographic Methods}

Plates coated with Mallinckrodt Reagent Grade Silicic Acid, 200 mesh, without binder, were used for the separation of neutral lipid and phospholipid classes.

Separation of triglyceride species or methyl esters of fatty acids of different degrees of unsaturation was done on plates coated $0.5-\mathrm{mm}$ thick with $16 \%$ silver nitrate in Silica Gel G. The plates were dried in air in the dark for approximately $2 \mathrm{hr}$, activated at $125 \mathrm{C}$ for 2 $\mathrm{hr}$, and stored over $\mathbf{P}_{2} \mathrm{O}_{5}$ in the dark.

Methyl esters were analyzed with a BarberColeman Model 10 gas chomatograph, equipped with a hydrogen flame detector and a $1 / 4$-in by 6 -ft column packed with $10 \%$ diethylene glycol succinate on Gas-Chrom P. The column temperature was $195 \mathrm{C}$, and the flow of carrier gas (argon) was approximately $60 \mathrm{ml}$ per minute.

\section{Preparation of Triglycerides}

Male albino rats weighing 190 to $200 \mathrm{~g}$ were obtained from Rawley Farms, maintained in the laboratory on Rockland Rat Diet for at least one week, and used before attaining a weight of $250 \mathrm{~g}$. Animals were killed by decapitation. The livers were removed and cooled on ice.

The livers were homogenized in a Waring Blendor in chloroform-methanol $(1: 2), 4 \mathrm{ml}$ per gram of wet tissue, for 2-3 min. A small amount of Santoquin (1,2-dihydro-6-ethoxy-2, 2,4-trimethylquinoline), approximately $1 \mathrm{mg}$ per 50 grams of tissue, was added to retard oxidation of polyunsaturated fatty acids. While the Blendor was still running, enough chloroform was added to make the final ratio of chloroform-methanol $(2: 1)$, followed after 1 to $2 \mathrm{~min}$ by water ( $1 \mathrm{ml}$ per gram of tissue).

The mixture was filtered through glass wool. The residue was washed with chloroformmethanol (2:1), and the combined filtrates were centrifuged. The cloudy chloroform layer was separated, cleared by the addition of methanol; the solvents were evaporated. To remove the water carried into the chloroform solution, the lipid was redissolved in chloroform-methanol (in some cases benzene-ethanol was used), and the solvent was evaporated. This was repeated until a clear oil was obtained as a residue.

Triglycerides were isolated from the total lipid extract by a modification of the procedure of Carroll (8). The lipid from approximately $100 \mathrm{~g}$ of liver was put on $200 \mathrm{~g}$ of Florisil (deactivated with $7 \%$ water) in hexane (Phillips technical grade, $99 \%$ hexane). Elution with $500 \mathrm{ml}$ of $4 \%$ diethyl ether in hexane removed some pigments and cholesterol esters. Triglycerides were then eluted with $1,250 \mathrm{ml}$ of $8 \%$ diethyl ether in hexane. The later fractions of triglyceride from this column were contaminated with a more polar lipid. They were combined and rechromatographed on a 30-g column, and the triglycerides were eluted with $500 \mathrm{ml}$ of $7 \%$ diethyl ether in hexane. The pure triglyceride fractions from the first and second columns were combined; the solvent was evaporated, and the triglycerides were dissolved in hexane. Final concentration was about $20 \mathrm{mg} / \mathrm{ml}$.

\section{Separation of Triglyceride Species}

The triglycerides, isolated as described above, were applied to a silver nitrate-Silica Gel G plate. Then 1-2 $\mathrm{mg}$ of the triglyceride fraction was used for the determination of the distribution of species. For preparative work 8-10 mg was loaded on each $20 \times 20 \mathrm{~cm}$ plate. The average load was $0.5 \mathrm{mg}$ per $\mathrm{cm}$ length of band. Two solvent systems were used in determining the distribution of species; diethyl ether-petroleum ether-benzene-methanol, $7.5: 30: 60: 1$, or chloroform-isopropanol, $98: 2$. The first system was used for all preparative work. After development the plates were sprayed with dichlorofluorescein in methanol and viewed under ultraviolet light. The bands were scraped into test tubes. A solution of $2 \% \mathrm{NaCl}$ in $20 \%$ water in methanol was added until the char- 
acteristic rose color of the dichlorofluoresceinsilver complex disappeared. Diethyl ether was added (ca. 10 times the volume of $\mathrm{NaCl}$ solution used), and the slurry was mixed on the Vortex mixer. The mixture was centrifuged and the ether decanted. The precipitate was extracted again with ether, and the ether extracts were combined for analysis.

\section{Positional Analysis of Triglycerides}

The positional distribution of fatty acids was determined by using pancreatic lipase, followed by selective phosphorylation of the 1,2diglycerides by diglyceride kinase as described previously (5). The following minor changes were made in the procedure. After lipase hydrolysis and thin-layer chromatography of the mono-, di-, and triglycerides the bands were made visible by spraying one edge of the plate with dichlorofluorescein while the rest of the plate was masked. This change was made after it was observed that spraying with $I_{2}$ led to some loss of the polyunsaturated acids. The diglycerides were eluted from the part of the plate not sprayed with dichlorofluorescein and used as substrate for the kinase reaction. The previous method (5) of calculating the amount of each methyl ester present (by using gas chromatography) was modified as recommended by Brandt and Lands (9). The retention times were measured from that point behind the real injection point where the width at half-height was actually zero.

The methyl esters of 14:0,16:0, 18:0, 20:0, $18: 1$, and $18: 2$ were identified by comparison of their retention times with those of the standards obtained from the Hormel Institute, Uni- versity of Minnesota, Austin, Minn. A plot of the logarithm of these retention times vs. the number of carbons in the fatty acid chain was made, and the equivalent chain-lengths of the other components were determined. They were compared with those found by Hofstetter et al. (10), and the acids were tentatively identified.

A mixture of methyl esters from the total triglyceride was then chromatographed on a silver nitrate-Silica Gel $G$ plate to separate the components according to the number of double bonds in the chains. The positions in which the esters were found on the silver nitrate plate corroborate the identifications made by equivalent chain-lengths for all the acids named in Table $I$. Four components were found which have 20 or 22 carbons, as shown by hydrogenation, and four or more double bonds. These components were still present after purification of the methyl esters on silicic acid plates. They were not found in blanks or in samples of Santoquin or of the residues remaining after evaporation of several liters of the solvents used. Their equivalent chain-lengths do not correspond well to any reported values, and they are indicated in this study as unidentified.

\section{RESULTS}

The distribution of fatty acids found for a sample of rat liver triglycerides is shown in Table I. The triglycerides contained up to $10 \%$ of fatty acids with 18 carbons and more than two double bonds, or with 20 or 22 carbons and from one to six double bonds. The sample shown in Table I contained $7.3 \%$ of such acids.

TABLE I

The Distribution of Fatty Acids Among the Positions of Rat Liver Triglycerides

\begin{tabular}{|c|c|c|c|c|c|c|c|c|}
\hline \multirow[b]{4}{*}{ Acid } & & & & \multirow[b]{3}{*}{ IV } & \multirow[b]{3}{*}{ V } & \multicolumn{3}{|c|}{$\underset{\text { Position }}{\underset{\text { Distribution }}{(\%)}}$} \\
\hline & \multicolumn{3}{|c|}{ Composition (mole $\%$ ) } & & & 1 & 2 & 3 \\
\hline & I & II & III & & & (V-III) & III & $(\mathrm{IV}-\mathrm{V})$ \\
\hline & TG & $\mathbf{P A}$ & MG & TG $\times 3$ & $\mathrm{PA} \times 2$ & 3 & 3 & 3 \\
\hline $14: 0$ & 1.4 & 1.4 & 1.1 & 4.2 & 2.8 & 0.6 & 0.4 & 0.5 \\
\hline $16: 0$ & 27.1 & 35.4 & 8.6 & 81.3 & 70.8 & 21 & 2.9 & 3.5 \\
\hline $16: 1$ & 3.0 & 1.6 & 4.0 & 9.0 & 3.2 & 0 & 1.3 & 1.9 \\
\hline 18:0 & 2.2 & 3.1 & 1.0 & 6.6 & 6.2 & 1.7 & 0.3 & 0.1 \\
\hline 18:1 & 30.0 & 28.9 & 39.6 & 90.0 & 57.8 & 6.1 & 13 & 11 \\
\hline $18: 2$ & 25.1 & 27.8 & 42.1 & 75.3 & 55.6 & 4.5 & 14 & 6.6 \\
\hline $\begin{array}{l}18: 3(n-6) \\
20: 0\end{array}$ & 0.1 & & 0.1 & 0.3 & & & & \\
\hline $18: 3(n-3)$ & 1.2 & 0.2 & 0.9 & 3.6 & 0.4 & & & \\
\hline $20: 1$ & 0.6 & & 0.1 & 1.8 & & & & \\
\hline $20: 2$ & 0.5 & & 0.2 & 1.5 & & & & \\
\hline $20: 3(n-9)$ & 0.2 & & 0.1 & 0.6 & & & & \\
\hline $20: 3(n-6)$ & 0.2 & & 0.2 & 0.6 & & & & \\
\hline $20: 4(n-6)$ & 1.5 & 0.9 & 1.2 & 4.5 & 1.8 & & & \\
\hline $20: 5(n-3)$ & 0.2 & & 0.1 & 0.9 & & & & \\
\hline $22: 4(n-6)$ & 0.6 & & 0.3 & 1.8 & & & & \\
\hline Unidentified & 2.1 & 0.6 & 0.7 & 6.3 & 1.2 & & & \\
\hline
\end{tabular}

LiPIDS, Vol. 3, No. 1 
TABLE II

Distribution of Acids in Several Samples of Rat Liver Triglycerides

\begin{tabular}{ccccc}
\hline & & \multicolumn{3}{c}{ Distribution (mole percentage) } \\
\cline { 3 - 5 } Sample & Acid & 1 & 2 & 3 \\
\hline I & $16: 0$ & 18 & 2.2 & 3.5 \\
& $16: 1$ & 1.2 & 0.7 & 0.4 \\
& $18: 0$ & 2.4 & 0.2 & 0 \\
& $18: 1$ & 6.6 & 13 & 12 \\
II & $18: 2$ & 4.0 & 16 & 13 \\
& $16: 0$ & 17 & 1.8 & 5.4 \\
& $16: 1$ & 0.3 & 0.6 & 2.0 \\
& $18: 0$ & 1.0 & 0.2 & 1.1 \\
& $18: 1$ & 8.0 & 12 & 12 \\
III & $18: 2$ & 7.5 & 17 & 7.3 \\
& $16: 0$ & 20 & 1.4 & 6.7 \\
& $16: 1$ & 0.3 & 0.9 & 3.1 \\
& $18: 0$ & 2.4 & 0.2 & 0.4 \\
& $18: 1$ & 5.6 & 13 & 14 \\
& $18: 2$ & 4.7 & 17 & 9 \\
\hline
\end{tabular}

- The analysis of each sample was performed three times.

Individually these components are present in amounts too small to analyze reliably through all the steps of the procedure; therefore they were not routinely reported in the determination of the distribution of acids.

Results from nine separate analyses, shown in Table II, indicate the reproducibility of the methods used. The values represent the averages of three separate analyses for each of the three different preparations of rat liver triglycerides. In all cases the saturated acids are found predominantly in the 1-position. The 2-position contains predominantly unsaturated acids, as has been shown before (11). In the 3 -position, unlike the $1-$, about $80 \%$ of the acids are unsaturated. The results were con-

TABLE III

Distribution of Fatty Acids Among the Three Positions of the Species SM2

\begin{tabular}{|c|c|c|c|c|}
\hline \multirow[b]{2}{*}{ Acid } & \multicolumn{4}{|c|}{ Position } \\
\hline & 1 & & 2 & 3 \\
\hline $14: 0$ & 0.7 & & 0.3 & 0.4 \\
\hline $16: 0$ & 22.9 & & 3.6 & 3.7 \\
\hline \multirow[t]{2}{*}{$18: 0$} & 0.6 & & 0.3 & 1.0 \\
\hline & 24.2 & & 4.2 & 5.1 \\
\hline \multirow{3}{*}{$18: 1$} & 0.2 & & 1.7 & 2.1 \\
\hline & 9.2 & & 26.8 & 25.2 \\
\hline & 9.4 & & 28.5 & 27.3 \\
\hline $\begin{array}{l}\text { Positional } \\
\text { isomer }\end{array}$ & & & & $\begin{array}{c}\text { Amount in } \\
\text { whole triglyceride }\end{array}$ \\
\hline SMM & 24.2 & & & 10.0 \\
\hline MSM & 4.2 & $\mathrm{x}$ & $\left.\frac{x .9}{3.5}\right)$ & 1.7 \\
\hline MMS & 5.1 & & $(33.5)$ & 2.1 \\
\hline
\end{tabular}

The values shown are averages of duplicate analyses of three different samples.
TABLE IV

Distribution of Acids Among the Three Positions of the Species $\mathrm{SD}_{2}$

\begin{tabular}{|c|c|c|c|c|}
\hline \multirow[b]{2}{*}{ Acid } & \multicolumn{4}{|c|}{ Position } \\
\hline & 1 & & 2 & 3 \\
\hline \multirow{3}{*}{$\begin{array}{l}16: 0 \\
18: 0\end{array}$} & 24.1 & & 1.4 & 2.4 \\
\hline & 1.5 & & 0.2 & 0.8 \\
\hline & 25.6 & & 1.6 & 3.2 \\
\hline \multirow{3}{*}{$\begin{array}{l}16: 1 \\
18: 1\end{array}$} & 1.0 & & 0.3 & 0.2 \\
\hline & 0.1 & & 1.8 & 3.0 \\
\hline & 1.1 & & 2.1 & 3.2 \\
\hline $18: 2$ & 6.9 & & 29.2 & 25.0 \\
\hline $\begin{array}{l}\text { Positional } \\
\text { isomer }\end{array}$ & & & & $\begin{array}{c}\text { Amount in } \\
\text { whole triglyceride }\end{array}$ \\
\hline SDD & 25.6 & & & 9.5 \\
\hline DSD & 1.6 & $\mathrm{x}$ & $\frac{1.3}{304}$ & 0.6 \\
\hline DDS & 3.2 & & & 1.2 \\
\hline
\end{tabular}

The values shown are averages of duplicate analyses of three different samples.

sidered to be sufficiently consistent for the conclusions made in this paper.

The total liver triglycerides were separated into species on plates containing silver nitrate, and the distribution of fatty acids in the major species was determined. Table III shows the distribution found for the species containing one saturated and two monounsaturated acids residues per molecule (the $\mathrm{SM}_{2}$ species). The relative amount of each positional isomer can be found from the limiting amount of saturated acids in the 1-, 2-, and 3-positions respectively. Thus the $\mathrm{SM}_{2}$ species represents $13.9 \%$ of the whole triglyceride fraction, and the relative amount of each positional isomer in the whole triglyceride is $10.0,1.7$, and $2.1 \%$ (Table III).

The analysis of the $\mathrm{SD}_{2}$ species (one saturated and two diunsaturated esters) is shown in Table IV. The $\mathrm{SD}_{2}$ species contain $11.3 \%$ of the whole triglyceride. The isomer SDD is predominant, $9.5 \%$ of all the triglycerides.

The SMD species (one saturated, one monounsaturated, and one diunsaturated ester per molecule) was found to consist principally of the SMD and SDM isomers (Table V).

\section{DIscussion}

For the species $\mathrm{SM}_{2}$ and $\mathrm{SD}_{2}$ the relative amount of each positional isomer present is obvious from the amount of $S$ at each position. This is not the case for the species SMD (Table V), as Brockerhoff has pointed out (12). In these experiments it was possible to estimate the relative amounts of the positional isomers of SMD without experimentally separating the pairs of enantiomers (13) because the total amount of one of these pairs, MSD 
and DSM, is limited by the very low amount of $\mathrm{S}$ in the 2-position. If the values of 0.5 and 0.7 are assumed for MSD and DSM respectively, the amount of SMD is equal to the amounts of $\mathrm{D}$ at the 3-position minus the amount of D contained in MSD, or 9.9. Assuming the limiting possible values of MSD, 0 or 1.2 , would give values of 10.4 or 9.2 respectively of SMD; that is, the value obtained for SMD is correct to \pm 0.7 regardless of the values assumed for MSD. The same reasoning applies to the values obtained for SDM.

The results shown in Tables I-V suggest that the system which acylates the 3-position uses 18:1 more effectively than $18: 2$ and either of these more effectively than 16:0. It may also preferentially esterify diglyceride units which contain certain fatty acids. The data on the relative amounts of each isomer make it possible to determine whether the acyl specificity is correlated to diglyceride composition or not. The consequences of correlative and noncorrelative specificity are summarized in Figure 2.

Consider that some acyl-CoA, $\mathrm{X}$, can be esterified to an SM diglyceride with a rate constant $\mathrm{k}_{\mathrm{SMX}}$ for the formation of SMX. Similarly $\mathrm{X}$ is added to SD diglycerides with a rate constant $\mathrm{k}_{\mathrm{SDX}}$, so also for the addition of a different acyl group, $\mathrm{Y}$, to the SM and SD diglycerides. Noncorrelative specificity exists if $\mathrm{k}_{\mathrm{SMX}} / \mathrm{k}_{\mathrm{SDX}}=\mathrm{k}_{\mathrm{SMY}} / \mathrm{k}_{\mathrm{SDY}}$. In this situation the ratio SMX/SMY will equal the ratio SDX/ SDY, and this will equal the ratio of $X$ in the 3-position of the triglyceride mixture over-all. In other words, the SM diglyceride will be distributed between SMX and SMY the same way that the SD diglyceride is distributed between SDX and SDY, and this distribution is the same as that of $\mathrm{X}$ and $\mathrm{Y}$ in the 3-position of all the triglycerides.

If, however, the acyl specificity were correlated to diglyceride composition, the distribution of $\mathrm{X}$ and $\mathrm{Y}$ between the SM derivatives would be different from the distribution for the SD derivative, or that of $\mathrm{X}$ and $\mathrm{Y}$ in the over-all mixture.

It seems clear that the synthesis proceeds with a noncorrelative specificity for the observed distributions are as follows:

$$
\frac{\mathrm{SMM}}{\mathrm{SMD}}=1.3 \quad \frac{\mathrm{SDM}}{\mathrm{SDD}}=1.3 \quad \frac{\mathrm{M}_{\mathrm{III}}}{\mathrm{D}_{\mathrm{III}}}=1.5
$$

Assuming noncorrelative specificity for the acylation of each position, the observed distribution of fatty acids in the total mixture was

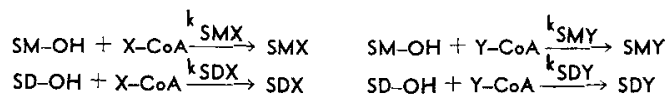

Correlative specificity:

Non-correlative specificity:

$\frac{{ }_{\text {SMX }}}{{ }_{\text {SMY }}} \neq \frac{k_{\text {SDX }}}{k_{\text {SDY }}}$
$\frac{\text { SMX }}{\text { SMY }} \neq \frac{\text { SDX }}{\text { SDY }} \neq \frac{X_{\text {III }}}{Y_{I I I}}$

FIG. 2. Correlative vs. noncorrelative specificity.

used to predict the relative amount of each species that could be isolated. For comparison, the same prediction was made assuming 1,3random-2-random acylation $(14,15)$, as shown in Table VI. Although the two hypotheses are opposed on a fundamental point, the metabolic equivalence of the 1- and 3-positions, the predictions made using them are not strikingly different. The principal difference is noted in species containing two saturated residues, which would require at least one saturate at either the 2- or 3-position, an unfavorable situation. Vander Wal indicated recently (16) that the calculated percentage composition of the triglycerides in a mixture would be relatively

TABLE V

Distribution of Acids Among the Three Positions of the Species SMD

\begin{tabular}{lrrr}
\hline & \multicolumn{3}{c}{ Position } \\
\cline { 2 - 4 } Acid & \multicolumn{1}{c}{1} & \multicolumn{1}{c}{3} \\
\hline $16: 0$ & 25.2 & 1.1 & 3.6 \\
$18: 0$ & 0.5 & 0.1 & 1.2 \\
\cline { 2 - 4 } & 25.7 & 1.2 & 4.8 \\
$16: 1$ & 1.1 & 0.8 & 0.4 \\
$18: 1$ & 3.7 & 11.8 & 17.0 \\
& 4.8 & -12.6 & 17.4 \\
$18: 2$ & 2.4 & 19.4 & 10.6 \\
\hline
\end{tabular}

Distribution corrected for amount of $\mathrm{M}_{3}$ and $\mathrm{M}_{2} \mathrm{D}$ present

\begin{tabular}{|c|c|c|c|c|}
\hline Acid & 1 & & 2 & 3 \\
\hline $\mathrm{s}$ & 25.7 & & 12 & 48 \\
\hline M & 3.8 & & 11.7 & 16.4 \\
\hline D & 2.2 & & 19.3 & 10.4 \\
\hline $\begin{array}{l}\text { Positional } \\
\text { isomer }\end{array}$ & & & & $\begin{array}{c}\text { Amount in } \\
\text { whole triglyceride }\end{array}$ \\
\hline SMD & 9.9 & & & 7.9 \\
\hline SDM & 15.8 & & 5.57 & 12.6 \\
\hline MSD & 0.5 & $\mathrm{x}$ & 0.3 & 0.4 \\
\hline MDS & 3.3 & & $(32.0)$ & 2.6 \\
\hline DSM & 0.7 & & & 0.6 \\
\hline DMS & 1.8 & & & 1.4 \\
\hline
\end{tabular}

The values shown are averages of duplicate analyses of three different samples.

LiPIDS, Vol. 3, No. 1 
TABLE VI

A Comparison of Observed and Predicted Distributions of Species in Triglycerides

\begin{tabular}{|c|c|c|c|}
\hline \multirow[b]{3}{*}{ Species } & \multicolumn{3}{|c|}{ Relative Abundance } \\
\hline & \multicolumn{2}{|c|}{ Predicted } & \multirow[b]{2}{*}{ Observed a $^{a}$} \\
\hline & $\begin{array}{c}\text { 1,3-R andom } \\
\text { 2-Random }\end{array}$ & $\begin{array}{l}\text { Noncorrelative } \\
\text { specificity }\end{array}$ & \\
\hline$S_{3}$ & 1.0 & 0.7 & 0.6 \\
\hline $\mathbf{S M}_{2}$ & 7.9 & 6.1 & 5.7 \\
\hline $\mathbf{S}_{3} \mathbf{M}$ & 11.4 & 13.5 & 13.9 \\
\hline $\mathrm{S}_{2} \mathrm{D}$ & 8.3 & 6.0 & 4.8 \\
\hline M: & 4.6 & $3: 9$ & 3.3 \\
\hline SMD & 20.2 & 24.6 & 25.5 \\
\hline $\mathrm{M}_{2} \mathrm{D}$ & 11.3 & 9.8 & 7.6 \\
\hline $\mathbf{S D}_{2}$ & 8.5 & 10.3 & 11.3 \\
\hline $\mathrm{MD}_{2}$ & 9.2 & 8.0 & 5.0 \\
\hline Polyunsaturated & 17.6 & 17.1 & 22.0 \\
\hline
\end{tabular}

- The observed values are averages of analyses of eight different samples.

little affected by large deviations from the 1,3random hypothesis.

The difference in the two assumptions is much more apparent however, when the relative abundance of the isomers is considered (Table VII). The isomers which are mirror images of each other are present in quite different amounts. The close agreement between the calculated and observed contents gives further support to the applicability of the concept of a noncorrelative specificity to rat liver triglycerides.

The actual combination of fatty acids which are used in a given reaction is governed both by the selectivities of the acyl transferases involved and by the composition of the pool of acyl-CoA's available for transesterification. The data obtained in this study do not allow one to assess the quantitative importance of each of these factors in determining triglyceride composition. It is possible that the acyl-CoA pool is compartmentalized, i.e., one set

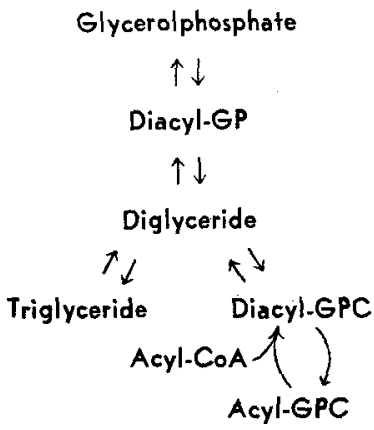
liver.
TABLE VII

A Comparison of Predicted and Observed Distribution of Positional Isomers of Triglycerides

\begin{tabular}{|c|c|c|c|c|}
\hline \multirow[b]{3}{*}{ Species } & \multirow[b]{3}{*}{ Isomer } & \multicolumn{3}{|c|}{ Distribution } \\
\hline & & \multicolumn{2}{|c|}{ Predicted } & \multirow[b]{2}{*}{ Observed } \\
\hline & & $\begin{array}{r}\text { 1,3-Random } \\
\text { 2-Random }\end{array}$ & $\begin{array}{c}\text { Noncorrelative } \\
\text { specificity }\end{array}$ & \\
\hline $\mathbf{S} \mathbf{M}_{2}$ & $\begin{array}{l}\text { SMM } \\
\text { MSM } \\
\text { MMS }\end{array}$ & $\begin{array}{l}5.3 \\
0.8 \\
5.3\end{array}$ & $\begin{array}{r}11.6 \\
0.6 \\
1.3\end{array}$ & $\begin{array}{r}10.0 \\
1.7 \\
2.1\end{array}$ \\
\hline $\mathrm{SD}_{2}$ & $\begin{array}{l}\text { SDD } \\
\text { DSD } \\
\text { DDS }\end{array}$ & $\begin{array}{l}4.1 \\
0.3 \\
4.1\end{array}$ & $\begin{array}{l}8.9 \\
0.3 \\
1.1\end{array}$ & $\begin{array}{l}9.5 \\
0.6 \\
1.2\end{array}$ \\
\hline SMD & $\begin{array}{l}\text { SMD } \\
\text { SDM } \\
\text { MSD } \\
\text { MDS } \\
\text { DSM } \\
\text { DMS }\end{array}$ & $\begin{array}{l}3.5 \\
6.1 \\
0.5 \\
6.1 \\
0.5 \\
3.5\end{array}$ & $\begin{array}{r}7.7 \\
13.6 \\
0.4 \\
1.5 \\
0.5 \\
0.9\end{array}$ & $\begin{array}{r}7.9 \\
12.6 \\
0.4 \\
2.6 \\
0.6 \\
1.4\end{array}$ \\
\hline
\end{tabular}

of acyl-CoA's is available for esterification to phospholipids and a different set for acylation of the 3-position of triglycerides. Therefore it has seemed more appropriate to use the term "system" in this discussion, including both acyl transferase specificity and availability of substrates, than to attribute the observed differences in composition entirely to differences in enzyme specificity.

Finally, the fatty acid distribution data enabled the authors to calculate the relative amounts of different 1,2-diglyceride units. The known interconversions of glycerolipids in liver are summarized in Figure 3 (17). Some of the diglyceride units may be derived directly from phosphatidic acids. However, no one has yet been able to demonstrate that the specificities of the acyl transferases which form phosphatidic acid are sufficient to account for the observed isomeric compositions of the derived phospholipids $(18,19)$. But the specifi-

TABLE VIII

The Distribution of 1,2-Diglyceride Species in Liver Diglycerides, Triglycerides, and Phospholipids

\begin{tabular}{cccc}
\hline & \multicolumn{3}{c}{ Distribution } \\
\cline { 2 - 4 } Species & Triglyceride & Diglyceride & Lecithin \\
\hline 00 & 4 & 5 & 1.8 \\
01 & 24 & 38 & 11.4 \\
11 & 8 & 12 & 2.0 \\
02 & 28 & 14 & 28.0 \\
12 & 14 & 5 & 6.5 \\
22 & 3 & & 2.1 \\
03 & & & 2.0 \\
13 & & 23 & 34.9 \\
04 & 19 & 4 & 9.6 \\
$<4$ double & & & \\
bonds & & & \\
\hline
\end{tabular}

a Elovson (21).

bLands and Hart (22). 
cities observed for the acyl transferases which modify diacyl GPC do account adequately for the observed composition.

Bjornstad and Bremer (20) have shown that in rat liver the CDP-choline:diglyceride cholinephosphotransferase reaction is readily reversible in vivo. This result leads one to wonder to what extent the diglyceride pool is influenced by the composition of the lecithins. Table VIII shows a comparison of the distribution of 1,2-diglyceride units in triglycerides, diglycerides, and lecithins. Some species have quite similar relative contents in the three different types of glyceride. For some of the species which are not similar, the relative amount in the diglyceride pool is greater than or less than in either the triglyceride or lecithin. This may be attributable simply to the fact that the data for diglycerides were obtained in another laboratory on a different strain of animals. There is, however, the alternative possibility that both systems which put substituents on the 3-position discriminate against, or use preferentially, certain diglyceride units.

\section{ACKNOWLEDGMENTS}

This work was supported in part by grant AM 05310 from the USPHS.

\section{REFERENCES}

1. Hirschmann, H. J., J. Biol. Chem. 235, 2762-2767 (1960).
2. Weiss, S. B., E. P. Kennedy and J. Y.. Kiyasu. J Biol. Chem. 235, 40-44 (1960).

3. Goldman, P., and P. R. Vagelos, J. Biol. Chem. $236,2620-2623$ (1961).

4. Gфransson, G., Biochem. J. 92, 41P-42P (1964).

5. Lands, W. E. M., R. A. Pieringer, S. P. M. Slakey and A. Zschocke, Lipids $1,444-448$ (1966).

6. Desnuelle, P., M. Constantin and J. Baldy, Bull. Soc. Chim. Biol. 37, 285-290 (1955).

7. Pieringer, R. A., and R. S. Kunnes, J. Biol. Chem. 240, 2833-2838 (1965).

8. Carroll, K. K., J. Lipid Res. 2, $135-141$ (1961).

9. Brandt, A. E., and W. E. M. Lands, to be published.

10. Hofstetter, H. H., N. Sen and R. T. Holman, JAOCS 42, 537-540 (1965).

11. Sahasrabudhe, M. R., lbid. 42, $862-864$ (1965).

12. Brockerhoff, H., Lipids 1,162 (1966).

13. Lands, W. E. M., and S. P. M. Slakey, Ibid. I, 295 (1966).

14. Vander Wal, R. J., JAOCS 37, 18-20 (1960).

15. Coleman, M. H., and W. C. Fulton, "The Enzymes of Lipid Metabolism," Pergamon Press, New York, 1961, P. Desnuelle, ed., p. 127-137.

16. Vander Wal, R. J., Adv. Lipid Res. 2, 1-16 (1964).

17. Kennedy, E. P., Ann. Rev, Biochem. 26, 119-148 (1957).

18. Lands, W. E. M., and P. Hart, J. Lipid Res. 5, 81-87 (1964).

19. Husbands, D. R.. and R. Reiser, Federation Proc. 25,405 (1966).

20. Bjornstad, P., and J. Bremer, J. Lipid Res. 7, 38-45 (1966).

21. Elovson, J., Biochim. Biophys. Acta 106, 480-494 (1965).

22. Lands, W. E. M., and P. Hart, JAOCS 43, 290-295 (1966).

[Received March 10, 1967] 